\title{
Validação da tecnologia educacional "abuso não vai rolar" para as jovens com deficiência intelectual
}

\author{
Validation of the educational technology "abuse no more" \\ for young people with intellectual disabilities
}

Keise Bastos Gomes da Nóbrega (http://orcid.org/0000-0002-5837-8183) ${ }^{1}$

Maria Wanderleya de Lavor Coriolano Marinus (https://orcid.org/0000-0001-7531-2605) ${ }^{1}$

Rosalie Barreto Belian (https://orcid.org/0000-0002-3978-4936) ${ }^{1}$

Daniela Tavares Gontijo (https://orcid.org/0000-0002-2117-0143) ${ }^{1}$

${ }^{1}$ Programa de PósGraduação em Saúde da Criança e do Adolescente, Centro de Ciências Médicas, Universidade Federal de Pernambuco. Av. Professor Moraes Rego 1.235, Cidade Universitária. 50670-901 Recife PE Brasil.

keise.nobrega@ufpe.br

\begin{abstract}
The implementation of educational actions, including sexual violence prevention, aimed to promoting the sexual rights of young individuals with intellectual disabilities, can be characterized as a huge challenge in the services that assist this population. This article aims to validate, with expert judges, educational technology aimed at sexual abuse prevention among young individuals with ID. This is a content and display validation study, performed with 25 judges. The information was collected through a questionnaire, considering the domains: objective, relevance, structure and presentation. The quantitative data were analyzed using the Content Validation Index (CVI) and a cutoff point of 0,80 was adopted, while qualitative data were submitted to thematic content analysis. An educational technology "Abuse no more: learning to protect yourself", was subsidized by Vigotsky's theoretical framework and consists of a set of materials, including a storybook and support resources (dolls, booklet and explanatory video). This technology was validated by the judges, with a total CVI of 0,99, obtaining a CVI $>0,95$ in all items and domains. The judges highlighted the relevant and innovative nature of the technology, offering suggestions for its improvement.
\end{abstract}

Key words Intellectual disability, Sex education, Young people, Educational technology, Sexual violence
Resumo A efetivação de ações educativas, incluindo a prevenção da violência sexual, direcionadas à promoção dos direitos sexuais das jovens com deficiência intelectual, caracteriza-se como um desafio nos serviços que atendem este público. O objetivo deste artigo é validar, com juizes especialistas, a tecnologia educacional direcionada à prevenção do abuso sexual entre as jovens com deficiência intelectual. Trata-se de estudo de validação de conteúdo e aparência, realizado com 25 juizes. As informações foram coletadas através de questionário, considerando os dominios: objetivo, relevância, estrutura e apresentação. Os dados quantitativos foram analisados através do Índice de Validação de Conteúdo (IVC) e adotado o ponto de corte 0,80 , enquanto os dados qualitativos foram submetidos à análise temática de conteúdo. A tecnologia educacional "Abuso não vai rolar: aprendendo a se proteger", foi subsidiada pelo referencial teórico de Vygotsky e é composta por um conjunto de materiais, incluindo livro de histórias e recursos de apoio (boneco, livreto e vídeo explicativo). Essa tecnologia foi validada pelos juizes, com um IVC total de 0,99, superior a 0,95 em todos os itens e dominios. Os juizes ressaltaram o caráter relevante e inovador da tecnologia, apresentando sugestões para sua potencialização.

Palavras-chave Deficiência intelectual, Educação sexual, Jovens, Tecnologia educacional, Violência sexual 


\section{Introdução}

No Brasil, 45.606.048 milhões de pessoas (24\%) declararam ter algum tipo de deficiência. Destas, 6.610.266 (14\%) são jovens com idades entre $15 \mathrm{e}$ 29 anos, sendo que 566.840 (9\%) têm deficiência intelectual (DI), foco de análise neste trabalho' ${ }^{1}$.

Contemporaneamente a deficiência é vista a partir da interação entre indivíduo e seu contexto, ou seja, sob a ótica da funcionalidade e da participação no seu meio. Essa perspectiva amplia o olhar sobre a deficiência, antes reduzida a uma condição de doença para assumir um caráter mais social e político, desfocando das incapacidades e limitações ${ }^{2}$.

Entre os diferentes desafios enfrentados por jovens com DI a vivência da sexualidade de forma saudável e segura se destaca ${ }^{3,4,5}$. As pessoas com deficiência têm direito de expressar e de viver a sua sexualidade, assim como de receber assistência em serviços especializados, acesso à informação e à educação sexual. A Convenção acerca dos Direitos das Pessoas com Deficiência defende que as jovens com deficiência devem ter proteção e liberdade para decidirem sobre sua sexualidade, de acordo com sua idade e maturidade. Para isto, os estados precisam adotar medidas para garantir o gozo destes direitos de forma igualitária, buscando empoderar essas jovens, promovendo o seu desenvolvimento de forma plena e saudável, livre de discriminação, imposição e violência ${ }^{5}$. Destaca-se que a sexualidade quando bem conduzida e orientada favorece o desenvolvimento afetivo, facilita a capacidade de se relacionar, melhora a autoestima e contribui para a inclusão social ${ }^{6-8}$.

Contudo, as pessoas com deficiência, muitas vezes, não são percebidas socialmente como pessoas sexualizadas, como se não pudessem entender ou necessitar de educação sexual. Como consequência, há uma postura de omissão ou mesmo de punição, na tentativa de ocultar e silenciar suas expressões de sexualidade ${ }^{6,7}$.

Este processo de silenciamento da sexualidade das pessoas com deficiência em geral, e sua consequente vulnerabilização, é amplificado quando se considera as especificidades da DI. Embora jovens com DI passem pelas mesmas transformações e fenômenos pubertários dos adolescentes típicos, os estereótipos sociais a elas associados, marcados pela percepção infantilizada e de dependência, contribuem para que sejam oferecidas poucas possibilidades de vivências, especialmente, no campo da sexualidade ${ }^{6,8}$. Os tabus sociais, estigmas e discriminações, dificultam o exercício pleno do direito de expressão da sexualidade, influenciando a autopercepção e o empoderamento, bem como repercutem negativamente para a apropriação do próprio corpo, a construção da identidade, inclusive sexual e de gênero?.

Neste contexto, vários jovens, principalmente as meninas, acabam não recebendo informações básicas sobre o seu desenvolvimento, incluindo as mudanças e cuidados com o seu corpo, fazendo com que fiquem inseguras e muitas vezes não saibam lidar com aspectos relacionados a sua sexualidade $^{3,4,9}$.

Este cenário assume contornos específicos quando se considera a interseccionalidade entre ser jovem, com deficiência e mulher. Estudos apontam que elas são menos informadas e mais expostas a fatores de risco como Infecções Sexualmente Transmissíveis (IST) e a violências, entre estas, o abuso sexual ${ }^{4,7,10}$. Esse tipo de violência pode levar a consequências psicológicas, fisiológicas, comportamentais, sociais e sexuais ao longo da vida. As vítimas estão propensas a apresentar, entre outros aspectos, depressão, ansiedade, encoprese, automutilação, isolamento social, problemas com a sexualidade, medos de ficar sozinhas, ideação suicida ${ }^{11}$.

O enfrentamento das situações de violência sexual perpassa pela adoção de estratégias para ampliar e fortalecer os mecanismos de defensoria das jovens. Dentre estas, destaca-se a importância da educação integral em sexualidade, na qual o educando é protagonista no processo educacional, o que possibilita a aquisição de conhecimentos, desenvolvimento de atitudes positivas e construção de habilidades para a vivência de uma sexualidade livre e segura ${ }^{12}$.

Ao considerar as especificidades de ser jovem com DI, o que implica na vivência de diferentes níveis de dificuldade de aprendizagem e participação social, além da escassez de Tecnologias Educacionais (TE) sobre a temática em foco, ressalta-se a importância do desenvolvimento e avaliação de materiais educativos adequados às necessidades e habilidades deste público ${ }^{13}$. Este estudo objetivou validar, com juízes especialistas, uma tecnologia educacional direcionada para a prevenção da violência sexual das jovens com DI.

\section{Método}

Este artigo apresenta a terceira etapa da pesquisa "Tecnologia assistiva educativa para a educação sexual de adolescentes do sexo feminino com deficiência intelectual", aprovada pelo Comitê 
de Ética em Pesquisas do Centro de Ciências da Saúde da Universidade Federal de Pernambuco.

A TE intitulada "Abuso não vai rolar: aprendendo a se proteger" foi elaborada em estudo metodológico de desenvolvimento e validação, com abordagem quantitativa e qualitativa, realizado em três etapas sequenciadas: diagnóstico, construção da TE e validação da TE (foco deste artigo).

$\mathrm{Na}$ primeira Etapa, diagnóstico, de cunho qualitativo, realizou-se entrevistas e grupos focais com 19 jovens mulheres com DI (15 a 18 anos), 17 mães/cuidadoras e 22 profissionais, com o propósito de compreender as concepções sobre sexualidade e educação sexual, além de identificar os temas e recursos que comporiam a TE. Identificou-se que o foco da TE seria a prevenção do abuso sexual. Na segunda etapa, desenvolveu-se a TE, tomando como base algumas fases do Guia de Orientação para Desenvolvimento de Projetos $(\text { GODP })^{14}$. A TE foi referenciada na Teoria sócio -histórica de Vygostky ${ }^{15}$, sendo considerados os pressupostos: interação social, participação ativa, linguagem, mediação, compensação, motivação, nível de desenvolvimento potencial e real.

A TE, ilustrada na Figura 1, é direcionada para utilização de profissionais e cuidadores/pais das adolescentes e tem o objetivo de facilitar o processo de ensino-aprendizagem para a prevenção do abuso sexual das jovens com DI, com idades entre 15 e 19 anos. A TE é composta por um livro ilustrado e dois bonecos sexualizados (homem e mulher), além de material de apoio nos formatos de livreto e vídeo explicativo.

O livro apresenta as histórias de Leca, uma adolescente com DI, que vivencia aspectos relacionados à sexualidade de forma segura e saudável, com o adolescente Edu. Ela se depara com situações de risco para o abuso sexual. Durante as histórias são oferecidos recursos de interatividade (perguntas, ilustrações para serem descobertas, espaços para desenhos etc.) que possibilitam que o mediador tanto avalie a compreensão e a aprendizagem das adolescentes como construa estratégias de proteção possíveis, com destaque para a busca de um adulto de confiança.

A terceira etapa, foco deste texto, constituise como uma pesquisa de validação de aparência e conteúdo realizada com juízes especialistas (profissionais, docentes e pesquisadores), que atingiram uma pontuação mínima de cinco pontos, conforme critérios adaptados do Modelo de Fehring ${ }^{17}$ : titulação, produção científica e experiência profissional com a temática em discussão. Os participantes foram identificados através da representatividade na área, do currículo na Plataforma Lattes e por "bola de neve", que consiste na seleção de sujeitos através de indicação e recomendação de sujeitos anteriores ${ }^{16}$.

Inicialmente, os juízes especialistas tiveram a oportunidade de manusear, observar, ler e analisar a TE. Posteriormente, responderam um questionário no qual avaliaram conteúdo e aparência de todo o kit que compõe a TE (livro, livreto de apoio, bonecos e vídeo explicativo). Os domínios de avaliação adotados foram baseados nos critérios de validação de materiais educativos, descritos como: objetivos, relevância, estrutura e apresentação ${ }^{18}$. Os itens foram analisados a partir de uma escala do tipo Likert: concordo (C), concordo parcialmente (CP), discordo parcialmente (DP), discordo (D) e não posso avaliar (NA). O grau de concordância entre os juízes foi avaliado pelo Índice de Validade de Conteúdo (IVC), considerando a concordância mínima de 0,80 para a validação ${ }^{19}$. O IVC foi utilizado para análise de cada domínio e da tecnologia como um todo.

Os juízes foram solicitados a fazer observações escritas acerca dos itens avaliados, além de sugestões para adaptação e melhoria do material. Estes dados foram submetidos à análise de conteúdo temática ${ }^{20}$, considerando os domínios de validação.

\section{Resultados}

Participaram do estudo 25 juízes especialistas com atuação em diferentes campos - docência, assistência, gestão e políticas públicas -, e graduação em diversas áreas (Quadro 1).

A maioria dos juízes tinha experiência na elaboração e/ou avaliação de materiais educativos/ educacionais, inclusive em formato de vídeos e documentários, sobre pessoas com deficiência e/ ou sexualidade e/ou violência. Destaca-se que alguns sujeitos eram autores de materiais referências na área, consultores do Ministério da Saúde, com trabalhos premiados, e também formadores na área de sexualidade e violência, reconhecidos nacionalmente.

Os dados dos questionários apontaram que a TE “Abuso não vai rolar” foi considerada válida, obtendo um IVC total de 0,99. Especificamente em relação ao livro, observa-se na Tabela 1, que todos os itens avaliados obtiveram concordância superior a 0,95 .

A dimensão objetivo, que se refere aos propósitos, metas ou fins que se deseja atingir com a utilização da TE, obteve uma concordância de 


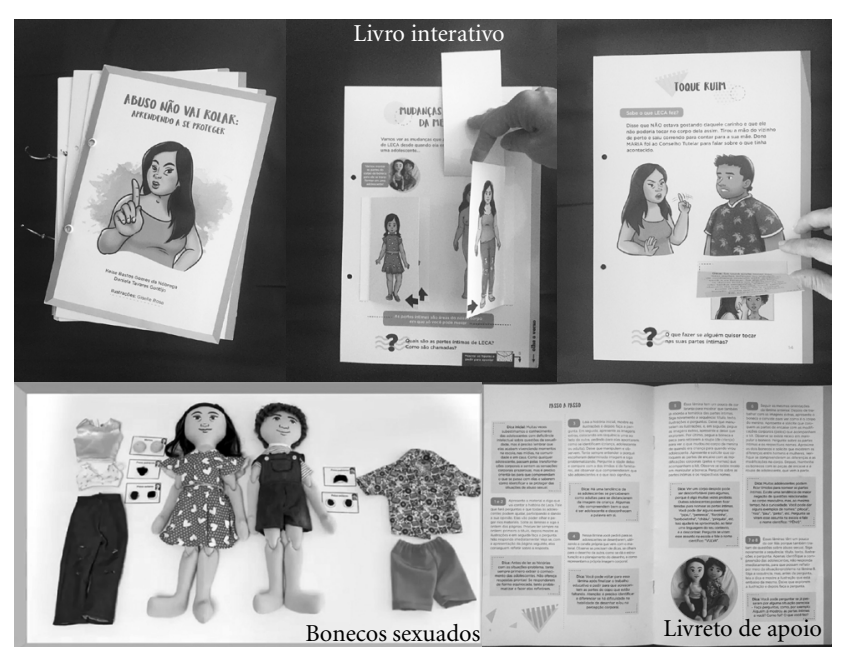

VÍDEO EXPLICATIYO DA TEENOLOGIA EDUCACIONAL "ABUSO NÃO VAI ROLAR: APRENDENDO A SE PBOTEGER"

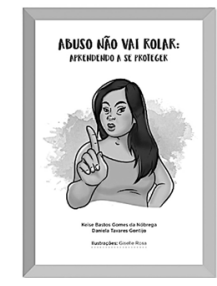

Vídeo explicativo

Figura 1. Apresentação da tecnologia educacional “Abuso não vai rolar: aprendendo a se proteger”.

Fonte: Arquivo pessoal.

$100 \%$. Alguns juízes destacaram o caráter inovador da TE e seu potencial para favorecer o ensino -aprendizagem das jovens com DI, para a prevenção do abuso sexual e para o desenvolvimento de estratégias de autoproteção.

Sem dúvida nenhuma o material é inovador e excelente, para trabalhar totalmente de forma concreta o abuso, ou melhor a proteção do abuso sexual na deficiência intelectual. (J4).

Outros juízes ressaltaram que a TE pode ser utilizada por profissionais de vários campos, e também não apenas com adolescentes com DI, uma vez que contribui para a identificação e prevenção de situações de abuso e a construção do diálogo com as vítimas.

Sugiro que esse material seja divulgado e fabricado para uso de conteúdo pedagógico, tanto para pessoas com deficiência intelectual, quanto para qualquer criança, jovem e mesmo adulto (PCD). (J9).

Excelente material que pode ser utilizado por profissional da área de saúde (...) psicólogos, equi- pes NASF e também pode ser utilizado nas escolas, serviço social, CREAS, facilitador como primeira abordagem. Sugiro que também seja utilizado na GPCA com devido treinamento. (J21).

Considerando a intenção de utilização futura da TE por pais, dois juízes ponderaram sobre a adequação da linguagem e a necessidade de realização da validação com este público.

Parabéns pela iniciativa! Oportunamente sugere-se escuta de pais para que avaliem a linguagem e compreensão. (J22).

Além de ser compreendida como uma TE que atinge a sua finalidade, foi considerada relevante e significativa obtendo um IVC $=1$. Os juízes realçaram a magnitude dos temas abordados e as possibilidades de compartilhamento e de aprendizado. Além disso, vislumbraram que o material poderá ser uma referência na área para ser utilizado por pais e profissionais na prevenção do abuso sexual.

Acredito que será de grande importância para os profissionais que trabalham com essa temática, 
Quadro 1. Caracterização dos juízes quanto às experiências, ocupação atual e experiência com elaboração e avaliação de materiais educacionais na área da pesquisa.

\begin{tabular}{|c|c|c|c|c|}
\hline $\mathbf{J}$ & $\begin{array}{l}\text { Tempo de } \\
\text { Experiência } \\
\text { (anos) }\end{array}$ & Experiência na área & Ocupação atual & $\begin{array}{c}\text { Elaboração/ } \\
\text { Avaliação de material }\end{array}$ \\
\hline $\mathrm{J} 1$ & 23 & $\begin{array}{l}\text { Conselho Tutelar e CAPSi, } \\
\text { Centro de referência a } \\
\text { crianças e adolescentes } \\
\text { vítimas de violência }\end{array}$ & Psicóloga & - \\
\hline $\mathrm{J} 2$ & 18 & $\begin{array}{l}\text { Professora de Direito Penal. } \\
\text { Perspectiva jurídica da } \\
\text { temática }\end{array}$ & $\begin{array}{l}\text { Professora do curso de } \\
\text { Direito }\end{array}$ & $\begin{array}{l}\text { Cartilha sobre crimes sexuais e } \\
\text { violência doméstica contra a } \\
\text { mulher }\end{array}$ \\
\hline $\mathrm{J} 3$ & 18 & $\begin{array}{l}\text { Assistência à crianças } \\
\text { e adolescentes } \\
\text { com deficiência; } \\
\text { Desenvolvimento de TA }\end{array}$ & $\begin{array}{l}\text { Professora do curso de } \\
\text { Terapia Ocupacional }\end{array}$ & $\begin{array}{l}\text { Avaliação e desenvolvimento } \\
\text { de produtos de TA para } \\
\text { crianças e adolescentes }\end{array}$ \\
\hline $\mathrm{J} 4$ & 6 & $\begin{array}{l}\text { Assistência em Terapia } \\
\text { Ocupacional e Pesquisa }\end{array}$ & Terapeuta Ocupacional & - \\
\hline J5 & 10 & $\begin{array}{l}\text { Inclusão educacional de } \\
\text { indivíduos com deficiência }\end{array}$ & $\begin{array}{l}\text { Professora do Departamento } \\
\text { de Psicologia e Orientação } \\
\text { Educacionais }\end{array}$ & $\begin{array}{l}\text { Elaboração de jogos de } \\
\text { alfabetização para crianças } \\
\text { com TEA }\end{array}$ \\
\hline J6 & 7 & $\begin{array}{l}\text { Escuta clínica de crianças } \\
\text { e adolescentes vítimas de } \\
\text { violência e transtornos } \\
\text { mentais }\end{array}$ & $\begin{array}{l}\text { Professora do curso de } \\
\text { Medicina e Psicóloga }\end{array}$ & - \\
\hline $\mathrm{J} 7$ & 4 & $\begin{array}{l}\text { Juíza de Direito titular } \\
\text { da Vara de Violência } \\
\text { Doméstica e Familiar } \\
\text { Contra a Mulher } \\
\end{array}$ & Juíza de Direito & - \\
\hline J8 & 17 & $\begin{array}{l}\text { Professora de Atendimento } \\
\text { Educacional Especializado }\end{array}$ & Pedagoga & $\begin{array}{l}\text { Desenvolve recursos } \\
\text { educacionais para crianças e } \\
\text { adolescentes com deficiência } \\
\end{array}$ \\
\hline J9 & 25 & $\begin{array}{l}\text { Professora de AEE } \\
\text { Educação profissional e } \\
\text { tecnológica inclusiva }\end{array}$ & Pedagoga & $\begin{array}{l}\text { Adequação de livros didáticos } \\
\text { voltados as pessoas com } \\
\text { deficiência intelectual } \\
\end{array}$ \\
\hline $\mathrm{J} 10$ & 10 & $\begin{array}{l}\text { Atendimento a adolescentes } \\
\text { em sofrimento psíquico e } \\
\text { deficiência intelectual no } \\
\text { CAPS }\end{array}$ & $\begin{array}{l}\text { Professora do curso de } \\
\text { Enfermagem }\end{array}$ & $\begin{array}{l}\text { Elaboração de material } \\
\text { educativo }\end{array}$ \\
\hline J11 & 5 & $\begin{array}{l}\text { Supervisora de estágio na } \\
\text { APAE } \\
\text { Voluntária na instituição } \\
\end{array}$ & $\begin{array}{l}\text { Professora do curso de } \\
\text { Fisioterapia }\end{array}$ & - \\
\hline $\mathrm{J} 12$ & 10 & $\begin{array}{l}\text { Desenvolvimento de } \\
\text { materiais educativos e } \\
\text { recursos terapêuticos }\end{array}$ & $\begin{array}{l}\text { Desenvolvedora de produtos } \\
\text { educativos e terapêuticos }\end{array}$ & $\begin{array}{l}\text { Produção de vídeos para pais e } \\
\text { profissionais; Conteúdo textual } \\
\text { em ambiente virtual }\end{array}$ \\
\hline $\mathrm{J} 13$ & 25 & $\begin{array}{l}\text { APAE, Oficina Abrigada de } \\
\text { Trabalho, IMG }\end{array}$ & $\begin{array}{l}\text { Gestora de serviço e } \\
\text { assistência } \\
\text { às famílias e pessoas com } \\
\text { deficiência }\end{array}$ & Cartilhas educativas \\
\hline
\end{tabular}

continu

bem como para a família, sendo um ótimo recurso a ser utilizado com estas adolescentes. (J13).

Mesmo que se tenha obtido índice necessário para sua validação, destaca-se a concordância parcial de quatro juízes com relação à abrangência da TE e a possibilidade de generalizações da aprendizagem para outros contextos. Neste sentido, o juiz de número $22 \mathrm{fez}$ ressalvas quanto ao 
Quadro 1. Caracterização dos juízes quanto às experiências, ocupação atual e experiência com elaboração e avaliação de materiais educacionais na área da pesquisa.

\begin{tabular}{|c|c|c|c|c|}
\hline $\mathbf{J}$ & $\begin{array}{c}\text { Tempo de } \\
\text { Experiência } \\
\text { (anos) }\end{array}$ & Experiência na área & Ocupação atual & $\begin{array}{c}\text { Elaboração/ } \\
\text { Avaliação de material }\end{array}$ \\
\hline $\mathrm{J} 14$ & 19 & $\begin{array}{l}\text { Educação sexual e } \\
\text { assistência a adolescentes } \\
\text { com deficiência intelectual }\end{array}$ & Psicóloga & $\begin{array}{l}\text { Documentário e cartilha } \\
\text { educativa sobre sexualidade de } \\
\text { jovens com DI }\end{array}$ \\
\hline $\mathrm{J} 15$ & 8 & $\begin{array}{l}\text { Formação em Educação } \\
\text { em Sexualidade. Vasta } \\
\text { experiência na área de } \\
\text { jornalismo televisivo e } \\
\text { comunicação audiovisual. }\end{array}$ & $\begin{array}{l}\text { Educadora Sexual: } \\
\text { formação e intervenção com } \\
\text { adolescentes }\end{array}$ & $\begin{array}{l}\text { Livro sobre prevenção } \\
\text { de violência sexual para } \\
\text { adolescentes }\end{array}$ \\
\hline J16 & 4 & $\begin{array}{l}\text { Desenvolvimento e } \\
\text { avaliação de produtos para } \\
\text { pessoas com deficiência }\end{array}$ & $\begin{array}{l}\text { Professora do curso de } \\
\text { Design }\end{array}$ & $\begin{array}{l}\text { Desenvolvimento e avaliação } \\
\text { de ferramentas para projetos } \\
\text { em TA }\end{array}$ \\
\hline $\mathrm{J} 17$ & 23 & $\begin{array}{l}\text { Atendimento em saúde a } \\
\text { crianças e adolescentes com } \\
\text { deficiências e síndromes } \\
\text { genéticas }\end{array}$ & Médica geneticista & - \\
\hline $\mathrm{J} 18$ & 4 & $\begin{array}{l}\text { Assistência em promoção } \\
\text { da saúde, cuidados com o } \\
\text { corpo, imagem corporal } \\
\text { e inclusão social para } \\
\text { adolescentes com DI }\end{array}$ & $\begin{array}{l}\text { Nutricionista } \\
\text { Professora do curso de } \\
\text { Nutrição }\end{array}$ & $\begin{array}{l}\text { Elaboração de Materiais } \\
\text { educativos sobre promoção da } \\
\text { saúde e cuidados com o corpo }\end{array}$ \\
\hline J19 & 3 & $\begin{array}{l}\text { Educação em Saúde; } \\
\text { Desenvolvimento de } \\
\text { materiais educativos }\end{array}$ & $\begin{array}{l}\text { Professora do curso de } \\
\text { Enfermagem }\end{array}$ & $\begin{array}{l}\text { Validação de protocolos } \\
\text { e materiais educativos; } \\
\text { Elaboração de tecnologias } \\
\text { educacionais, vídeos educativos }\end{array}$ \\
\hline $\mathrm{J} 20$ & 5 & $\begin{array}{l}\text { Projeto de prevenção } \\
\text { e enfrentamento da } \\
\text { violência, no contexto } \\
\text { escolar }\end{array}$ & $\begin{array}{l}\text { Professora do Departamento } \\
\text { de Educação e PPG em } \\
\text { Educação, Culturas e } \\
\text { Identidades } \\
\end{array}$ & $\begin{array}{l}\text { Cartilha sobre a prevenção } \\
\text { de abuso sexual; Guia de } \\
\text { estimulação de crianças com } \\
\text { deficiência }\end{array}$ \\
\hline $\mathrm{J} 21$ & 33 & $\begin{array}{l}\text { Assistência a crianças e } \\
\text { adolescentes vítimas de } \\
\text { violência }\end{array}$ & $\begin{array}{l}\text { Médica clínica e legista } \\
\text { Sanitarista }\end{array}$ & $\begin{array}{l}\text { Materiais educativos sobre } \\
\text { violência }\end{array}$ \\
\hline $\mathrm{J} 22$ & 24 & $\begin{array}{l}\text { Gestão de sistemas de } \\
\text { saúde com foco para } \\
\text { atenção a criança e ao } \\
\text { adolescente }\end{array}$ & $\begin{array}{l}\text { Médico sanitarista, gestão e } \\
\text { pesquisador }\end{array}$ & $\begin{array}{l}\text { Materiais educativos sobre } \\
\text { saúde da criança e do } \\
\text { adolescente }\end{array}$ \\
\hline $\mathrm{J} 23$ & 15 & $\begin{array}{l}\text { Assessora para a área de } \\
\text { DI; Desenvolvedora de } \\
\text { conteúdo sobre DI }\end{array}$ & $\begin{array}{l}\text { Ministério das Relações } \\
\text { Exteriores }\end{array}$ & $\begin{array}{l}\text { Elaboração de materiais } \\
\text { educativos e produção de } \\
\text { conteúdo textual para pessoas } \\
\text { com DI e cuidadores }\end{array}$ \\
\hline $\mathrm{J} 24$ & 6 & $\begin{array}{l}\text { Educação sexual e violência } \\
\text { sexual }\end{array}$ & $\begin{array}{l}\text { Gerente de parcerias para a } \\
\text { saúde inclusiva na América } \\
\text { Latina }\end{array}$ & - \\
\hline $\mathrm{J} 25$ & 23 & Médico da Special Olympics & $\begin{array}{l}\text { Diretor de programa de } \\
\text { saúde inclusiva }\end{array}$ & - \\
\hline
\end{tabular}

Fonte: Elaborado pelas autoras.

potencial de representatividade do material, considerando a diversidade humana, inclusive das jovens com DI, além de diferentes contextos, as- pectos sócio-históricos e econômicos e amplitude de situações de risco. Contudo, ele compreende que um único material não poderia dar conta 
Tabela 1. Índice de validade quanto aos domínios: objetivo, relevância, estrutura e apresentação.

\begin{tabular}{|c|c|c|c|c|c|c|}
\hline Itens & $\mathrm{C}$ & CP & DP & D & NA & IVC \\
\hline \multicolumn{7}{|l|}{ Objetivo } \\
\hline $\begin{array}{l}\text { 1.1 Tem como propósito a prevenção do abuso sexual das adolescentes com } \\
\text { deficiência intelectual }\end{array}$ & 24 & 1 & - & - & - & 1 \\
\hline $\begin{array}{l}\text { 1.2 Favorece o ensino-aprendizagem das adolescentes com deficiência } \\
\text { intelectual }\end{array}$ & 25 & 0 & - & - & - & 1 \\
\hline $\begin{array}{l}\text { 1.3. Estimula o reconhecimento do corpo, a identificação de situações de } \\
\text { risco para o abuso sexual e o desenvolvimento de estratégias de proteção a } \\
\text { partir de situações-problema }\end{array}$ & 25 & 0 & - & - & - & 1 \\
\hline $\begin{array}{l}\text { 1.4 Contribui com pais e profissionais, na educação sexual com o foco na } \\
\text { prevenção do abuso sexual das adolescentes com deficiência intelectual }\end{array}$ & 23 & 2 & - & - & - & 1 \\
\hline IVC Total & & & & & & 1 \\
\hline
\end{tabular}

\section{Estrutura e apresentação}

2.1 A tecnologia educacional é apropriada em sua estrutura e forma de apresentação

2.2 As informações são apresentadas de maneira clara e objetiva

$2.3 \mathrm{O}$ conteúdo das informações apresentadas está cientificamente correto

$2.4 \mathrm{O}$ material está apropriado ao nível sociocultural do público alvo proposto

2.5 Há uma sequência lógica do conteúdo proposto

2.6 Os recursos auxiliares contribuem para a compensação das dificuldades e permitem o acesso aos diferentes níveis de compreensão

2.7 O conteúdo apresentado corresponde ao nível de conhecimento do público-alvo

2.8 Estimula a interação, a participação ativa e a comunicação

2.9 A formatação, cores, gramatura, imagens estão adequadas ao públicoalvo

2.10 As ilustrações, símbolos e signos, são representativos e expressivos suficientes

$2.11 \mathrm{O}$ material de que é feito está apropriado, facilita a exploração e a interação

2.12 A quantidade de informação está suficiente

IVC Total

\section{Relevância}

3.1 Permite o compartilhamento de conhecimento e generalizações do aprendizado em outros contextos

3.2 Favorece o desenvolvimento de atitudes preventivas diante de situações de risco

3.3 Aborda temas relevantes para a prevenção do abuso sexual das adolescentes com deficiência intelectual

3.4 Valoriza conhecimentos já adquiridos e estimula novos conhecimentos 3.5 Pode ser utilizado como referência no meio científico da área e por instituições que trabalham as adolescentes com deficiência intelectual

IVC Total

$\begin{array}{cccccc}24 & 1 & - & - & - & 1 \\ 21 & 4 & - & - & - & 1 \\ 24 & 1 & - & - & - & 1 \\ 20 & 5 & - & - & - & 1 \\ & & & & & \\ 24 & 1 & - & - & - & 1 \\ 22 & 3 & - & - & - & 1 \\ & & & & & \\ 19 & 6 & - & - & - & 1 \\ & & & & & 1 \\ 24 & 1 & - & - & - & 1 \\ 21 & 3 & 1 & - & - & 0,96 \\ & & & & & \\ 21 & 3 & 1 & - & - & 0,96 \\ & & & & & 1 \\ 25 & 0 & - & - & - & 1 \\ 23 & 2 & - & - & - & 1 \\ & & & & & 0,99\end{array}$

$\begin{array}{llllll}21 & 4 & - & - & - & 1 \\ 23 & 2 & - & - & - & 1 \\ 25 & 0 & - & - & - & 1 \\ 24 & 1 & - & - & - & 1 \\ 22 & 3 & - & - & - & 1\end{array}$

Fonte: Elaborada pelas autoras.

da totalidade destes aspectos e que há, portanto, a necessidade de se fazer recortes e escolhas.

A crítica relacionada à situação de abuso com imagens e cenas mais comuns e frequentes promove "generalizações" não adequadas para todos os casos. Por outro lado, opções diferentes da proposta geram mais críticas que o formato atual. (J22).
No que se refere à estrutura e apresentação do livro, ou seja, a forma de demonstrar as orientações, sua organização geral, disposição, coerência e formatação, o IVC foi de 0,99 . Os juízes destacaram as possibilidades de diversificação e graduação do conhecimento, interatividade, acessibilidade e a qualidade do material. 
Para além da relevância social, percebe-se o cuidado com que o material educativo avaliado foi pensado e confeccionado, com uma estratégia de abordagem apropriada, apresentando as informações de maneira clara e objetiva, seguindo uma sequência lógica de acordo com os assuntos abordados, valorizando os conhecimentos adquiridose estimulando novos conhecimentos, bem como facilitando o acesso a um público com diferentes níveis de compreensão. (J7).

Congruente ao que foi apontado em relação à abrangência da TE, considerando a diversidade do público, observou-se que cinco juízes concordaram parcialmente nos itens referentes à apropriação sociocultural, considerando as possíveis dificuldades de compreensão e do manejo dos mediadores.

Não sei se temos elementos para afirmar que o material é apropriado ao nível sociocultural sem a aplicação do mesmo em grupos com diferentes níveis socioeconômicos. (J5).

[...] concordo parcialmente pois há a colocação de questões delicadas que acho que o material de apoio poderia trazer um suporte de conteúdo maior, quando o mediador for os pais, por exemplo, que podem ter um nível de escolaridade/compreensão menor. (J16).

Outros seis juízes também apontaram concordância parcial, quanto à adequação ao nível de conhecimento das adolescentes, refletindo sobre as variações de níveis de DI e compreensão das jovens.

Acredito que sim, mas tenho dúvida se permite o acesso aos diferentes niveis de compreensão se ainda não foi aplicado com esse público. (J5).

Sugiro que defina o grau de deficiência intelectual para adequar a linguagem. (J6).

Alguns especialistas apresentaram propostas para a inclusão de temas como métodos contraceptivos e prevenção de IST, e a inclusão dos serviços de saúde como referência na rede de cuidados e espaços de assistência. Os juízes 15 e 21 trouxeram à tona a importância de reflexões sobre aspectos relacionados ao consentimento na deficiência intelectual, a não culpabilização da vítima de abuso, a possibilidade do prazer na situação de abuso e a importância do autoconhecimento.

Toques que são permitidos, autoconhecimento, sexualidade presente e toques que não são permitidos a própria adolescente também fazer no outro. $O$ toque do próprio namorado Edu, pode ser um toque ruim se não for consentido. (J21).

Houve também proposições de melhorias, sem comprometimento com a validação obtida, nas ilustrações do material para a aprimorar o design, a interatividade e o foco, de forma a potencializar para a assimilação da mensagem visual.

No item 2.9 me coloco parcial pois há caixas de texto que achei de baixo contraste, como nas páginas 17 e 20. (J16).

Todos os materiais de apoio também foram avaliados em suas especificidades e objetivos, e tiveram um índice de validade de conteúdo concordante, livreto (IVC 1), bonecos (IVC 1) e vídeo (IVC 0,99), como mostra a Tabela 2.

Os juízes evidenciaram a importância dos materiais de apoio para que a TE atenda a sua finalidade, destacando a potencialização do alcance com a utilização de dois canais de comunicação (livreto e vídeo). Ocorreu a discordância de apenas um juiz que considerou o vídeo desnecessário.

Muito bom ter dois materiais de apoio, são bem complementares. O escrito impresso tem mais informações e fundamentação, já o vídeo fica mais interativo, atinge um público maior. (J3).

Em relação ao livreto, foram dadas sugestões para uma linguagem mais simples e objetiva, pensando em atingir mediadores de diferentes níveis de escolaridade.

Considero apropriado para os profissionais. Para os pais/familiares talvez necessite de ajustes considerando a amplitude de perfis e niveis de escolaridade. (J22).

Por fim, os juízes ressaltaram as contribuições dos bonecos para a ação educativa, principalmente no que se refere à introdução de maior ludicidade e incentivo à participação.

A presença dos bonecos favorece a informação contextualizada com o uso do objeto concreto, o que pode auxiliar a compreensão e a expressão. (J5).

\section{Discussão}

Os resultados indicam que a TE, "Abuso não vai rolar" foi validada com elevado índice geral de concordância, uma vez que todos os itens e domínios avaliados - objetivos, estrutura e aparência, relevância -, obtiveram o IVC superior a 0,95. Esta concordância foi balizada pelos dados qualitativos apresentados neste estudo.

As tecnologias têm a finalidade de facilitar o processo educacional formal e informal, conjugando teoria e prática, conhecimentos e saberes. Podem ser artefatos, recursos, processos, utilizados nas ações educacionais, que passam por procedimentos fundamentados e sistematizados de construção e validação ${ }^{21}$. 
A validação é um dos mecanismos para o desenvolvimento de materiais eficazes, pois avalia se estes atingiram seus objetivos e metas, se são acessíveis e apropriados ao público-alvo, o quanto são significativos para a área de intervenção e sua aplicabilidade ${ }^{18}$. A diversidade de olhares no momento de validação, conforme observada no presente estudo, é relevante e favorável para a construção de um material mais completo e efetivo $^{21,22}$. Neste sentido, observou-se que mesmo a versão apresentada aos juízes considerada válida, estes realizaram críticas construtivas para o aprimoramento da $\mathrm{TE}$, que serão discutidas aqui e consideradas na versão final.

Em relação aos domínios objetivo e relevância, os juízes destacaram consensualmente que a tecnologia atinge os seus propósitos, por apresentar o potencial em contribuir no processo educativo para a identificação de situações de risco e na busca de comportamentos autoprotetivos.

Considerando que as jovens com DI são mais vulneráveis ao abuso sexual e às potenciais consequências negativas dessa violência, propostas educacionais que trabalhem o desenvolvimento de atitudes de autoproteção e de identificação de situações de risco e de violência são relevantes e necessárias ${ }^{7,23,24}$.
Identificou-se que em alguns países existem programas e recursos específicos para a educação sexual de pessoas com $\mathrm{DI}^{25}$. Contudo, a literatura indica a necessidade de adequação desses materiais, da sensibilização da sociedade para a sexualidade das pessoas com DI, da inclusão e do aprimoramento dos programas de educação sexual nos currículos escolares e da capacitação dos profissionais e familiares ${ }^{8,23}$. No Brasil, a educação sexual de jovens com DI ainda é muito incipiente. Há falta de recursos, de profissionais capacitados e da adesão familiar, além dos tabus sociais que ainda perduram e dificultam essa prática.

O conhecimento sobre a escassez de materiais educativos adequados para jovens com DI fez com que os participantes ressaltassem a característica inovadora da TE e sua relevância para o campo. No entanto, corroborando com alguns juízes, compreende-se que é necessário fazer ressalvas quanto às possibilidades de abrangência e generalização dos conhecimentos construídos com a utilização da TE, considerando não só a diversidade humana, incluindo os diferentes níveis cognitivos, mas também as situações vivenciadas em diferentes contextos de vida.

Reflete-se que a compreensão das jovens com DI sobre as questões da sexualidade não está rela-

Tabela 2. Índices de validade do livreto de apoio, dos bonecos e do vídeo explicativo.

\begin{tabular}{|c|c|c|c|c|c|c|}
\hline Itens & C & $\mathrm{CP}$ & DP & D & NA & IVC \\
\hline \multicolumn{7}{|l|}{ Livreto } \\
\hline Orienta de forma satisfatória para a utilização da tecnologia educacional & 23 & 2 & - & - & - & 1 \\
\hline A linguagem está apropriada & 23 & 2 & - & - & - & 1 \\
\hline Contém as informações necessárias & 22 & 3 & - & - & - & 1 \\
\hline $\begin{array}{l}\text { É um material relevante na composição da tecnologia educacional } \\
\text { IVC Total }\end{array}$ & 25 & - & - & - & - & $\begin{array}{l}1 \\
1\end{array}$ \\
\hline \multicolumn{7}{|l|}{ Bonecos } \\
\hline $\begin{array}{l}\text { Facilitam o processo de ensino- aprendizagem para a prevenção do abuso } \\
\text { sexual }\end{array}$ & 23 & - & - & - & 2 & 1 \\
\hline $\begin{array}{l}\text { A concepção e apresentação dos bonecos contribui para o ensino- } \\
\text { aprendizagem e a exploração }\end{array}$ & 23 & - & - & - & 2 & 1 \\
\hline Despertam o interesse e a motivação & 23 & - & - & - & 2 & 1 \\
\hline $\begin{array}{l}\text { São recursos relevantes na composição da tecnologia educacional } \\
\text { IVC Total }\end{array}$ & 23 & - & - & - & 2 & $\begin{array}{l}1 \\
1\end{array}$ \\
\hline \multicolumn{7}{|l|}{ Vídeo } \\
\hline Orienta de forma satisfatória para a utilização da tecnologia educacional & 23 & - & - & - & 2 & 1 \\
\hline A linguagem está apropriada & 22 & 1 & - & - & 2 & 1 \\
\hline Contém as informações necessárias & 23 & - & - & - & 2 & 1 \\
\hline É um material relevante na composição da tecnologia educacional & 22 & - & - & 1 & 2 & 0,96 \\
\hline
\end{tabular}

Fonte: Elaborada pelas autoras. 
cionada apenas as dificuldades cognitivas, mas a influências sociais, culturais, históricas, de como essa adolescente é percebida pela família e no seu meio social ${ }^{26,27}$. Assim, o direito a receber educação sexual é para todas, sendo importante desenvolver estratégias que alcancem a diversidade deste grupo.

Neste sentido, uma das estratégias utilizadas na TE foi a indicação para que seja utilizada em grupo, tendo em vista as possibilidades de interação social e aprendizagens. Conforme destaca $V_{y g o s t k y}{ }^{28}$, o homem deve ser entendido mediante as relações que estabelece em sociedade, sendo sujeito de transformação de si e do mundo. $\mathrm{O}$ autor valorizava as habilidades da pessoa com deficiência por acreditar que formam a base para a aprendizagem e para o desenvolvimento. Assim, acredita-se que as dificuldades cognitivas podem ser "compensadas" com ricas experiências de interação social. Para o autor, [...] lo que es imposible en el plano del desarrollo individual, se torna posible en el plano del desarrollo social. (p.247). Assim, jovens com mais habilidades podem colaborar para a aprendizagem daquelas com mais dificuldade e esse processo será benéfico para ambas.

Além disso, considerando a diversidade dos níveis de comprometimento pela DI e os diferentes perfis sociais associados a esta condição, a TE foi elaborada de forma a possibilitar que o mediador gradue as informações no que tange a sua complexidade, manejando a ação educativa, oferecendo os estímulos adequados e maximizando as habilidades. Conforme destaca Dey et al. ${ }^{29}$ a partir do conhecimento prévio trazido pelo aprendiz sobre o tema, o processo de mediação deve construir novos conhecimentos, como se fosse um andaime, fornecendo um alicerce para a pessoa com DI alcançar outros patamares de aprendizagem.

Um último ponto em relação aos objetivos e relevância da TE, alguns juízes especialistas sugeriram, e será acatado na continuidade desta pesquisa, a realização da validação com o público-alvo: pais, profissionais que atuam com as adolescentes e as próprias adolescentes com DI. Contudo, é relevante ressaltar que a tecnologia em foco foi gestada (primeira fase - diagnóstico) a partir da escuta desse público, o que amplifi$\mathrm{ca}$, de forma significativa, a possibilidade de que seja também validada por estes, corroborando a avaliação dos juízes com ampla experiência no campo em discussão.

No que tange ao domínio da estrutura e apresentação, foram realizadas sugestões e reflexões para o aprimoramento relacionadas às ilustrações e ampliação do conteúdo temático do livro. Quanto às ilustrações, identificou-se sugestões para potencializar a aprendizagem, a congruência destas com o conteúdo do texto e a identificação das adolescentes com as histórias propostas.

Acredita-se que as imagens contribuem para a aprendizagem, uma vez que o público-alvo fica mais interessado e motivado pelas informações. $\mathrm{Na}$ construção do material, buscou-se a apresentação de imagens que fossem representativas e significativas para jovens com DI. Contudo, é importante observar que as informações visuais estão implicadas em convenções ligadas a cultura, sendo necessário avaliar o processo de significação que cada adolescente dará às ilustrações do livro a fim de potencializar o processo educativo $^{30}$.

Em relação às sugestões de conteúdo na TE, argumenta-se que na educação sexual existem diversas temáticas que devem ser abordadas com as jovens com DI. Diante da complexidade de informações que envolve cada assunto, é preciso haver um direcionamento do material educativo para que não seja extenso e tenha sua usabilidade prejudicada. Este direcionamento foi norteado pelos dados obtidos nas etapas precedentes à validação que geraram a TE em foco.

No entanto, considera-se que algumas inclusões ou ajustes temáticos, sugeridos pelos juízes, precisam ser discutidas e incorporadas à TE. Uma delas, refere-se à necessidade de abordar a questão do consentimento, pertinente a todos os públicos, no campo da sexualidade.

A capacidade de consentir uma relação afetiva ou sexual das pessoas com DI pode ser exercitada através da educação sexual, com a aquisição de conhecimentos e habilidades para a autoproteção e para poder fazer escolhas conscientes. $\mathrm{O}$ importante é não interditar, mas possibilitar a tomada de decisão de forma apoiada.

A Convenção sobre os Direitos das Pessoas com Deficiência ${ }^{31}$ refere que seja reconhecido o direito das pessoas com deficiência, em idade de contrair matrimônio, de casar-se e estabelecer família, com base no livre e pleno consentimento dos pretendentes. Contudo, a materialização desse novo paradigma ainda é um desafio. A deficiência continua a ser vinculada à incapacidade e dependência. Portanto, é preciso ocorrer também uma mudança na forma com que são vistos, ou seja, como pessoas, com direitos e deveres, que precisam ser respeitadas e empoderadas para se apropriarem do seu potencial decisório e de autogestão ${ }^{32}$. 
Diante disso, observou-se a importância de se deixar esta questão mais explícita no livro, através de ajustes nas ilustrações e no conteúdo, que destaquem que o toque do namorado também poderia não ser agradável e que a adolescente tem autonomia para não consentir. Ainda em relação ao toque, concorda-se com a necessidade de abordagem dos processos de autoconhecimento e masturbação na tecnologia em discussão.

Outro ponto destacado por alguns juízes, e que resultarão em alterações no material, se refere a ajustes que possibilitem reforçar a possibilidade de ocorrência das situações de abuso por alguém conhecido pelas adolescentes.

É reconhecido que as jovens com deficiência são mais expostas a violências, inclusive ao abuso sexual ${ }^{10,11,26}$. Algumas delas estão fora da escola e pessoas de seu convívio podem aproveitar a oportunidade para abusar sexualmente. Além disso, as jovens podem ter dificuldade de compreender e comunicar o fato ocorrido, assim como ter medo do abandono e perda do lar. Muitas nem sabem que têm o direito de negar um comportamento abusivo por não receberem educação sexual e pelo estigma da incapacidade, são desacreditadas quando são confrontadas, gerando reincidência do abuso. Além de tudo, são mulheres, havendo uma intersecção de vulnerabilidades, em que o gênero feminino tem um histórico de discriminação e desvantagens que, sobrepostas, aumentam os riscos de abuso sexual ${ }^{25}$.

Outra reflexão trazida pelos juízes se refere à importância de não restringir a compreensão do abuso como situações nas quais se associam a dor física. O sentido do abuso sexual é diferente para cada pessoa, dependendo das suas experiências e vivências. A tendência social é colocar o abusador no lugar de "monstro" (com uma imagem negativa), mas a vítima pode não o perceber dessa maneira ${ }^{33}$.

Além disso, a relação de dependência de cuidados das pessoas com deficiência lhes imprime a ideia de que o seu corpo pode ser manuseado por cuidadores, inclusive, para aquelas que são institucionalizadas, fazendo com que fiquem mais vulneráveis às situações de violência sexual. As vítimas criam uma ideação do cuidador como alguém que lhes proporciona zelo e proteção, gerando uma confusão de sentimentos entre cuidado, carinho e abuso, que dificultam a identificação e revelação da violência ${ }^{34}$.

Dessa forma, percebe-se a necessidade da educação sexual de forma acessível para que as jovens com DI tenham acesso à informação, desenvolvam habilidades de comunicação e apren- dam estratégias de proteção para uma vida segura e plena ${ }^{12}$. Para isso, as práticas de educação sexual precisam ampliar suas propostas de intervenção para além de serem informativas, serem formativas, no sentido de fortalecer essas adolescentes enquanto pessoas.

Nestes aspectos, serão realizados ajustes na tecnologia para ampliar a compreensão de que nem todo abuso sexual provoca dano físico ou dor. Reitera-se que a TE proposta aborda as possibilidades de sedução, como a oferta de carona e de guloseimas, enquanto situações de risco para abuso sexual.

Corrobora-se com a preocupação de alguns juízes quanto a importância de se desconstruir, no processo educativo, a culpabilização da vítima pelo abuso. Nesse sentido, será feito ajuste de um trecho considerado ambíguo para enfatizar que a culpa não é da adolescente. $O$ sentimento de culpa constitui-se em uma das barreiras para a denúncia dos casos de abusos sexuais. Diante de uma sociedade misógina, patriarcal e discriminatória, as mulheres vítimas de abuso sexual, muitas vezes, são culpabilizadas e/ou se sentem culpadas ${ }^{35}$. Portanto, deve-se enfatizar que a vítima em sentido algum deve ser vista como culpada e colocar, veementemente, a responsabilidade no agressor.

Uma última sugestão seria a ideia de destacar e ampliar a rede de apoio para os casos em que, durante a utilização do material, se identifique situações de abuso. Considerando o cuidado pautado na articulação intrassetorial e intersetorial dos diversos sistemas (saúde, assistência social, educação, proteção e defesa $)^{36}$, serão adicionadas mais referências nos materiais de apoio para que se potencialize o acesso a esta rede de proteção.

No que se refere ao material de apoio, houve concordância quanto a necessidade, importância e relevância destes, tanto em forma de vídeo quanto impresso, para uma melhor apropriação do tema e para a condução do processo educativo com a tecnologia.

Considerando o despreparo e a necessidade de maior informação dos mediadores, pais ou mesmo os profissionais, a utilização de materiais de apoio pode contribuir para o conhecimento e fornecer subsídios no processo educativo. A existência de dois materiais de apoio adveio justamente da necessidade de abranger diferentes formas de interagir com os mediadores, sendo o livreto mais denso e fundamentado, enquanto o vídeo oferece uma linguagem mais informal e prática. A ideia com a disponibilização do vídeo, congruente com outros estudos que discutem 
essa ferramenta educativa ${ }^{37}$, é apresentar a TE de maneira mais rápida, objetiva e acessível, principalmente, para os mediadores com dificuldade de leitura.

Os bonecos sexualizados também foram considerados pelos juízes como relevantes e adequados para a educação sexual das jovens com DI. Esta percepção é corroborada por estudos que defendem que as TE devem possibilitar experiências mais realistas e concretas, com diversidade de recursos e estímulos multissensoriais, modelos representativos e autoexpressivos, ensaios e problematização, têm se mostrado efetivas, no processo de ensino-aprendizagem de pessoas com $\mathrm{DI}^{23,24}$.

\section{Considerações finais}

A TE “Abuso não vai rolar” foi validada pelos juízes especialistas em relação aos seus objetivos, relevância, estrutura e apresentação. Os participantes avaliaram que a TE proposta irá colaborar com pais e profissionais na educação sexual das jovens com DI. Elucidaram que o material tem potencial para ser referência técnico-científica na área da sexualidade e violência para jovens com
DI, podendo ser utilizado em serviços assistenciais e educacionais.

Ressalta-se a importância do envolvimento do mediador - pais e profissionais - no processo educacional. Há a necessidade de sensibilização e motivação para utilizar a TE a partir do que é sugerido nos materiais de apoio, adaptando a cada realidade e demandas das adolescentes, que também são participantes ativas no processo.

Apesar da participação fundamental do público-alvo e suas colaborações na primeira fase (diagnóstico) da pesquisa é reconhecida a necessidade de validação da TE desenvolvida com as adolescentes, pais e profissionais, portanto, uma limitação do presente estudo. No entanto, este processo encontra-se em execução, e os resultados serão apresentados em publicação futura.

Espera-se que este estudo possa inspirar outros profissionais para o desenvolvimento de tecnologias educacionais e sua validação, contribuir para a emancipação das pessoas com deficiência e promoção de direitos, estimular a educação sexual e prevenir o abuso sexual, alertar sobre a maior ocorrência dessa violência em pessoas vulneráveis, especialmente, as jovens com deficiência intelectual, além de ampliar o conhecimento científico e a difusão sobre o tema da sexualidade.

\section{Colaboradores}

KBG Nóbrega foi responsável pela concepção, planejamento, coleta, análise e redação do texto. RB Belian e MWLC Marinus contribuíram na concepção e na revisão crítica do artigo, DT Gontijo orientou o processo da pesquisa, redação e revisão do texto. 


\section{Agradecimentos}

Às adolescentes, mães/cuidadoras e profissionais que participaram da pesquisa. Aos serviços de referência que autorizaram e facilitaram o processo de coleta de dados. Ao Núcleo de Tecnologia Assistiva (NTA) do Centro de Ciências da Saúde da Universidade Federal de Pernambuco/Laboratório de Tecnologia Assistiva do Departamento de Terapia Ocupacional (LabTATO) e Núcleo de Estudos e Pesquisas em Vulnerabilidade e Saúde na Infância e Adolescência (NEPVIAS) pelas contribuições no processo de desenvolvimento da tecnologia educacional.

\section{Referências}

1. Instituto Brasileiro de Geografia e Estatística (IBGE). Censo Demográfico 2010. [acessado 2016 set 7]. Disponível em: http://www.ibge.gov.br/home/estatistica/ populacao/censo2010/default.shtm

2. Gaudenzi P, Ortega F. Problematizando o conceito de deficiência a partir das noções de autonomia e normalidade. Cien Saude Coletiva 2016; 21(10):3061-3070.

3. Jahoda A, Pownall, J. Sexual understanding, sources of information and social networks: the reports of young people with intellectual disabilities and their non-disabled peers. J Intellect Disabil Res 2014; 58(5):430441.

4. Nelson B, Pettersson KO, Emmelin M. Experiences of teaching sexual and reproductive health to students with intellectual disabilities. Sex Education 2020; 20 (4):1-15

5. United Nations. Promotion and protection of human rights: human rights questions, including alternative approaches for improving the effective enjoyment of human rights and fundamental freedoms [Report of the 3rd Committee: General Assembly, 72nd session]. New York: UN, 7 Dec; 2017. p. 170.

6. Billeke $\mathrm{CH}$, Veja CA, Briones AB, Soto HI, Paillán KL. Manifestaciones afectivas en jóvenes con discapacidad intelectual. Interdisciplinaria 2018; 35(1):69-86.

7. Goli S, Noroozi M, Salehi M. A comprehensive sexual health care program for educable intellectually disabled adolescent girls: protocol for a mixed methods study. Reproductive Health 2018; 15:1-8.

8. Frawley P, Bigby C. I'm in their shoes: experiences of peer educators in sexuality and relationship education. Int J Dev Disabil 2014; 39(2):167-176.

9. Bernert DJ, Ogletree RJ. Women with intellectual disabilities perceptions of sex. J Intellect Disabil Res 2013; 57(Pt 3):240-249.

10. Deslandes SF, Vieira LJES, Cavalcanti LF, Silva RM. Health care of children and adolescents in situation of sexual violence, in four Brazilian capitals. Interface (Botucatu) 2016; 20(59):865-877.

11. Gil-llario MD, Morell-Mengual V, Díaz-Rodríguez I, Ballester-Arnal R. Prevalence and sequelae of self-reported and other-reported sexual abuse in adults with intellectual disability. J Intellect Disabil Res 2019; 63(Pt 2):138-148.

12. United Nations Educational Scientific and Cultural Organization (UNESCO). International technical guidance on sexuality education: an evidence-informed approach. Revised edition. France; 2019.

13. Pedro KM, Chacon MCM. Softwares educativos para alunos com deficiência intelectual: estratégias utilizadas. Rev Bras Ed Esp 2013; 19(2):195-210.

14. Merino GSAD. GODP-Guia de orientação para Desenvolvimento de Projetos: uma metodologia de design centrado no usuário [Internet]. Florianópolis: Ngd/ UFSC; 2016. [acessado 2018 out 17]. Disponível em: www.ngd.ufsc.br

15. Vygotsky L. A Construção do Pensamento e da Linguagem. tradução Paulo Bezerra. 2a ed. São Paulo: Martins Fontes; 2009.

16. Polit DF, Beck CT, Hungler B. Fundamentos de pesquisa em enfermagem: métodos, avaliação e utilização. Porto Alegre: Artmed; 2011. 
17. Fehring RJ. Methods to validate nursing diagnoses. Heart \& Lung 1987; 16(6):625-629.

18. Leite SS, Áfio ACE, Carvalho LV, Silva JM, Almeida PC, Pagliuca LMF. Construção e validação de instrumento de validação de conteúdo educativo em saúde. Rev Bras Enferm 2018; 71(Supl. 4):1732-1738.

19. Polit, D.F.; Beck C.T. The content validity index: are you sure you know what's being reported? Critique and recommendations. Res Nurs Health 2006; 29(5):489-497.

20. Bardin L. Análise de conteúdo. São Paulo: Edições 70; 2011.

21. Wild CFW, Nietsche E, Salbego C, Teixeira E, Favero NB. Validação de cartilha educativa: uma tecnologia educacional na prevenção da dengue. Rev Bras Enferm 2019; 72(5):1385-1392.

22. Monteiro RJS, Paula M, Oliveira CA, Belian RB, Lima LS, Santiago ME, Gontijo DT. DECIDIX: meeting of the Paulo Freire pedagogy with the serious games in the field of health education with adolescents. Cien Saude Coletiva 2018; 23(9):2951-2962.

23. McDaniels B, Fleming A. Sexuality education and intellectual disability: time to address the challenge. Sex Disabil 2016; 34:215-225.

24. Ballan MS, Freyer MB. The sexuality of young women with intellectual and developmental disabilities: a neglected focus in the American foster care system. Disabil Health J 2017; (10):371-375.

25. United Nations Population Fund (UNFPA). Young persons with disabilities: global study on ending gender -based violence and realising sexual and reproductive health and rights. New York. 2018 Jul. 430 p.

26. Jones L, Bellis MA, Wood S, Hughes K, McCoy E, Eckley L, Bates G, Mikton C, Shakespeare T, Officer A. Prevalence and risk of violence against children with disabilities: a systematic review and meta-analysis of observational studies [Published Online]. Lancet 2012; 380:899-907.

27. Pownall J, Wilson S, Jahoda A. Health knowledge and the impact of social exclusion on young people with intellectual disabilities. J Appl Res Intellect Disabil 2020; 33:29-38.

28. Vygotsky L. Obras Escogidas: V fundamentos da defectologia. Madrid: Visor Distribuciones; 2012.

29. Dey P, Panda A, Banerjee M. Impact of Vygotskian Intervention on Persons with Intellectual Impairment. Psychol Stud 2014; 59(3):278-83.

30. Houts PS, Doak CC, Doak LG, Loscalzo MJ. The role of pictures in improving health communication: A review of research on attention, comprehension, recall, and adherence. Patient Educ Couns 2006; 61(2):173190.
31. Brasil. Decreto no 6.949 de 25 de agosto de 2009. Promulga a Convenção Internacional sobre os Direitos das Pessoas com Deficiência e seu Protocolo Facultativo, assinados em Nova York, em 30 de março de 2007. Diário Oficial da União; 26 ago 2009.

32. Figueiredo AC. Desafios à implementação do novo paradigma da capacidade jurídica das pessoas com deficiência. Revista Deficiência Intelectual 2019; 15 (Ano 9):21-27.

33. Santos, BR. Por uma escuta da criança e do adolescente social e culturalmente contextualizada: concepções de infância e de adolescência, universalidade de direitos e respeito às diversidades. In: Santos BR, Goncalves IB, Vasconcelos G, organizadores. Escuta de crianças e adolescentes em situação de violência sexual. Brasília, DF: EdUCB; 2014. p.27-42.

34. Byrne G. Prevalence and psychological sequelae of sexual abuse among individuals with an intellectual disability: A review of the recent literature. J Intellect Disabil 2018; 22(3):294-310.

35. Lima F, Farias M, Plutarco L. A metamorfose da identidade de vítimas de estupro. Salud Soc 2017; 8(3): 264-274.

36. Brasil. Ministério da Saúde (MS). Secretaria de Atenção à Saúde. Departamento de Ações Programáticas e Estratégicas. Metodologias para o cuidado de crianças, adolescentes e famílias em situação de violência. Brasília: MS; $2014.86 \mathrm{p}$.

37. Prawesti I, Haryanti F, Lusmilasari L. Effect of health education using video and brochure on maternal health literacy. Belitung Nurs Jl 2018; 4(6):612-618.

38. Schaafsma D, Kok G, Stoffelen JMT, Leopold Curfs LMG. Identifying effective methods for teaching sex education to individuals with intellectual disabilities: a systematic review. J Sex Res 2015; 52(4):412-432.

Artigo apresentado em 30/04/2020

Aprovado em 20/04/2021

Versão final apresentada em 22/04/2021

Editores-chefes: Romeu Gomes, Antônio Augusto Moura da Silva 